\title{
Characterization of LGR5 expression in poorly differentiated colorectal carcinoma with mismatch repair protein deficiency
}

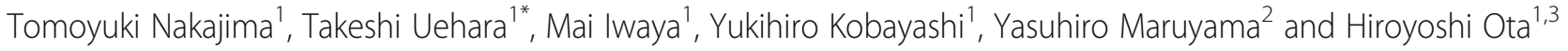

\begin{abstract}
Background: Leucine-rich repeat-containing G-protein-coupled receptor 5 (LGR5) is a promising intestinal stem cell and carcinoma stem cell marker. We examined the relationship between mismatch repair (MMR) protein deficiency and LGR5 expression in poorly differentiated (PD) colorectal carcinoma (CRC).

Methods: In 29 cases of PD-CRC, deficiencies in MMR proteins (MLH1, PMS2, MSH2, MSH6) and $\beta$-catenin expression were identified by immunohistochemistry (IHC). LGR5 expression was examined by the RNAscope assay in tissue microarrays.

Results: LGR5 H-scores in MMR-deficient (MMR-D) cases were significantly lower than those in MMR-proficient (MMR-P) cases $(P=0.0033)$. Nuclear $\beta$-catenin IHC scores in MMR-D cases were significantly lower than those in MMR-P cases $(P=0.0024)$. In all cases, there was a positive correlation between $L G R 5 \mathrm{H}$-score and nuclear $\beta$-catenin IHC score $(r=0.6796, P<0.001)$. Even in MMR-D and MMR-P cases, there was a positive correlation between $L G R 5$ $\mathrm{H}$-score and nuclear $\beta$-catenin IHC score $(r=0.7180, P<0.0085$ and $r=0.6574, P<0.003$, respectively). MMR-D CRC cases showed low expression of LGR5, which may be due to low activation of the Wnt/ $\beta$-catenin signaling pathway.

Conclusions: Our results reveal the relationship between LGR5 expression and MMR protein profiles in PD-CRC. A further study is warranted to confirm these findings.
\end{abstract}

Keywords: Leucine-rich repeat-containing G-protein-coupled receptor 5, Mismatch repair, Poorly differentiated colorectal carcinoma, RNA in situ hybridization

\section{Background}

Leucine-rich repeat-containing G-protein-coupled receptor 5 (LGR5) is a promising intestinal stem cell marker [1]. LGR5 is also a candidate marker for colorectal cancer (CRC) stem cells [2] and may be closely involved in the progression and prognosis of CRC [3]. However, Jang et al. suggested a suppressive role for LGR5 in CRC progression [4].

\footnotetext{
* Correspondence: tuehara@shinshu-u.ac.jp

1 Department of Laboratory Medicine, Shinshu University School of Medicine, 3-1-1 Asahi, Matsumoto 390-8621, Japan

Full list of author information is available at the end of the article
}

CRC is one of the most common carcinomas worldwide [5] and is graded into well, moderately, and poorly differentiated types according to gland structures. The colon carcinogenesis model is roughly divided into an adenoma-carcinoma sequence and a serrated neoplasia pathway involving microsatellite instability (MSI) [6] [7]. Approximately $70-80 \%$ of CRCs have APC inactivation, which has a major role in adenoma formation, and subsequent multistage mutations such as KRAS and TP53 mutations that cause carcinogenesis [8]. MSI is a hypermutable phenotype caused by abnormalities in DNA repair. Mismatch repair (MMR) proteins such as MLH1, MSH2, MSH6, and PMS2 are inactivated, and gene

C C The Author(s). 2020 Open Access This article is licensed under a Creative Commons Attribution 4.0 International License, which permits use, sharing, adaptation, distribution and reproduction in any medium or format, as long as you give appropriate credit to the original author(s) and the source, provide a link to the Creative Commons licence, and indicate if changes were made. The images or other third party material in this article are included in the article's Creative Commons licence, unless indicated otherwise in a credit line to the material. If material is not included in the article's Creative Commons licence and your intended use is not permitted by statutory regulation or exceeds the permitted use, you will need to obtain permission directly from the copyright holder. To view a copy of this licence, visit http://creativecommons.org/licenses/by/4.0/ The Creative Commons Public Domain Dedication waiver (http://creativecommons.org/publicdomain/zero/1.0/) applies to the data made available in this article, unless otherwise stated in a credit line to the data. 
mutations accumulate. Lynch syndrome patients suffer from germline mutations in MMR-related genes, which induce tumors such as CRC [9]. Methylation in the promoter regions of MMR genes promotes suppression of MMR protein expression, defining a carcinogenesis pathway of CRC that differs from the classic adenomacarcinoma sequence [10]. The overwhelming majority of these cases are caused by hypermethylation of the $M L H 1$ promoter [11].

Poorly differentiated (PD)-CRC has a poor prognosis compared with well and moderately differentiated CRC [12]. However, PD-CRC with MSI has a low lymph node metastasis rate and shows a good prognosis [13], although the mechanisms that define its clinicopathological differences have not yet been clarified. In this study, a new analysis focusing on LGR5-positive carcinoma stem cells was performed to investigate differences in prognosis based on a carcinogenesis model of PD-CRC. We also investigated the relationship between $L G R 5$ and $\beta$-catenin expression related to LGR5 regulation, and that between CD8positive tumor-infiltrating lymphocytes (CD8 + TILs) and $L G R 5$ expression in immune responses.

\section{Methods}

\section{Patients and materials}

A total of 625 CRC patients were selected at Shinshu University Hospital, Matsumoto, Japan from 2004 to 2014. PD-CRC was defined as the majority of the tumor being occupied by a PD-CRC component. All 29 PD-CRC cases were selected from the above patients. The clinicopathological features of these cases were evaluated.

\section{Histopathology, immunohistochemical staining, and evaluation}

All samples were fixed in $8 \%$ formaldehyde and paraffin tumor blocks were made. Tumor blocks of CRC were selected to prepare a tissue microarray (TMA). The most representative region of each CRC sample was selected. Tissue cores were punched out from each block using thin-walled 3-mm stainless steel needles (Azumaya Medical Instruments Inc., Tokyo, Japan), and arrayed on a recipient paraffin block. Serial sections of 4- $\mu$ m thickness cut from these blocks were stained with hematoxylin and eosin (HE) or immunostained with antibodies against MLH1 (ES05, mouse monoclonal; dilution, 1:50; Agilent Technologies, Santa Clara, CA, USA), PMS2 (EP51, rabbit monoclonal; dilution, 1:40; Agilent Technologies), MSH2 (FE11, mouse monoclonal; dilution, 1:50; Agilent Technologies), MSH6 (EP49, rabbit monoclonal; dilution, 1:50; Agilent Technologies), $\beta$-catenin (mouse monoclonal; dilution, 1:500; BectonDickinson \& Company, Franklin Lakes, NJ, USA), or CD8 (CD8/144B, mouse monoclonal; dilution 1:50; Dako, Copenhagen, Denmark). For antigen retrieval, sections were boiled in $0.05 \%$ citraconic anhydride solution pH 7.4 (Immunosaver; Nissin EM, Tokyo, Japan) for 45 min for MLH1, PMS2, MSH2, and MSH6, or microwaved in $0.45 \%$ Tris $/ 5 \mathrm{mM}$ EDTA for $25 \mathrm{~min}$ for $\beta$ catenin and CD8. Detection of MMR proteins was performed using a NovoLink polymer detection system (Leica Microsystems GmbH, Wetzlar, Germany) and that of $\beta$-catenin and CD8 was performed using an Envision detection system (Agilent Technologies) according to the manufacturers' recommendations.

In accordance with a previous report [14], the immunohistochemical staining for MLH1, PMS2, MSH2, and MSH6 was scored as positive when a nuclear staining pattern was observed. In addition, at least $5 \%$ of tumor cells in individual tissue cores were required to be stained. Cases of PD-CRC were determined to have MMR protein deficiency when at least one of MLH1, PMS2, MSH2, and MSH6 was negative.

$\beta$-Catenin staining was evaluated as previously described [15]. The results were calculated as IHC scores, where IHC score $=$ percentage of nuclear positive cells $\times$ staining intensity. Nuclear staining was classified into five grades from 0 to 4 . We defined staining intensity as follows: 0 , negative; 1 , weak; 2 , moderate; 3 , strong; and 4 , very strong. The nuclear $\beta$-catenin IHC score ranged from 0 to 400. The number of CD8+ TILs was calculated in the three most infiltrated fields for each case using an intermediate-power field.

\section{LGR5 RNA in situ hybridization}

Detection of LGR5 mRNA was performed with an RNAscope $^{\bullet}$ kit (Advanced Cell Diagnostics, Hayward, CA, USA) according to the manufacturer's instructions using unstained sample tissue slides. Briefly, tissue sections were pretreated by heating and protease was applied prior to hybridization with an LGR5-specific probe. The detailed procedure was described in a previous publication [16]. Brown dots present in the nucleus and/or cytoplasm were recognized as positive staining. LGR5 expression was quantified using a five-level scoring system recommended by the manufacturer ( 0 , no staining; 1, 1-3 dots/cell; 2, 4-10 dots/cell; 3, > 10 dots/cell; 4, > 15 dots/cell with $>10 \%$ of dots in clusters). The H-score was calculated as: ( $\%$ of grade 1 cells $\times 1)+(\%$ of grade 2 cells $\times 2)+(\%$ of grade 3 cells $\times 3)+(\%$ of grade 4 cells $\times 4)$. The overall $\mathrm{H}$-score for each patient was calculated based on the H-score per high-power field (400× magnification). Furthermore, any cell with one or more dots was regarded as LGR5-positive.

\section{Statistical analysis}

Statistical analysis was performed using JMP version 10 (SAS Institute Japan, Tokyo, Japan). Spearman's rank correlation coefficient analysis was used to assess 
correlations. The Wilcoxon rank sum test or chi-square test was also applied to assess statistical significance. A value of $P<0.05$ was considered significant.

\section{Results}

\section{Correlations between clinicopathological factors and} MMR protein expression

We first evaluated the expression of MMR proteins (MLH1, PMS2, MSH2, and MSH6) in 29 PD-CRC cases. Among the cases, 17 were MMR protein-proficient (MMR-P) and 12 were MMR protein-deficient (MMR-D) adenocarcinoma. In detail, 11 MMR-D cases showed dual loss of MLH1 and PMS2 and one MMR-D case showed dual loss of MSH2 and MSH6. Representative images and staining of MMR-D and MMR-P cases are shown in Fig. 1. Table 1 summarizes the correlations between clinicopathological factors and MMR protein expression. MMR-D cases were significantly correlated with age, tumor site, lymph node metastasis, pathological stage, and CD8+ TILs (Fig. 2a, b, d, e).

\section{LGR5 RNA expression in PD-CRC with MMR protein deficiency}

We evaluated $L G R 5$ expression in all PD-CRC cases. All 29 cases contained carcinoma cells with some LGR5positive dots, with a wide range of $L G R 5$-positive cell staining. Representative images of LGR5 staining in MMR-D and MMR-P cases are shown in Fig. 2c and f. $L G R 5 \mathrm{H}$-scores varied among the cases. Mean $\mathrm{H}$-scores for LGR5 staining in MMR-P and MMR-D cases were 62.9 (24.2-136.2) and 24.4 (7.9-63.4), respectively. LGR5
Table 1 Correlation between clinicopathological factors and MMR protein expression

\begin{tabular}{|c|c|c|c|c|}
\hline & \multirow[t]{2}{*}{$n$} & \multicolumn{2}{|c|}{ MMR protein } & \multirow[t]{2}{*}{$P$-value } \\
\hline & & Proficient & Deficient & \\
\hline \multicolumn{5}{|l|}{ Sex } \\
\hline Male & 14 & 7 & 7 & \multirow[t]{2}{*}{0.363} \\
\hline Female & 15 & 10 & 5 & \\
\hline \multicolumn{5}{|l|}{ Age } \\
\hline$\geq 71$ & 15 & 12 & 3 & \multirow[t]{2}{*}{$0.016^{*}$} \\
\hline$<71$ & 14 & 5 & 9 & \\
\hline \multicolumn{5}{|l|}{ Tumor site } \\
\hline Proximal & 17 & 7 & 10 & \multirow[t]{2}{*}{$0.023^{*}$} \\
\hline Distal & 12 & 10 & 2 & \\
\hline \multicolumn{5}{|c|}{ Lymphovascular invasion } \\
\hline Absent & 0 & 0 & 0 & \multirow[t]{2}{*}{ NA } \\
\hline Present & 29 & 17 & 12 & \\
\hline \multicolumn{5}{|c|}{ Lymph node metastasis } \\
\hline Absent & 9 & 0 & 9 & \multirow[t]{2}{*}{$<0.001^{*}$} \\
\hline Present & 20 & 17 & 3 & \\
\hline \multicolumn{5}{|c|}{ Pathological stage } \\
\hline$\leq \mathrm{pT} 2$ & 7 & 0 & 7 & \multirow[t]{2}{*}{$<0.001^{*}$} \\
\hline > pT3 & 22 & 17 & 5 & \\
\hline \multicolumn{5}{|l|}{ CD8+ TILs } \\
\hline$\leq 155.7$ & 15 & 15 & 0 & \multirow[t]{2}{*}{$<0.001^{*}$} \\
\hline$>155.7$ & 14 & 2 & 10 & \\
\hline
\end{tabular}

TIL tumor-infiltrating lymphocytes * $P<0.05$

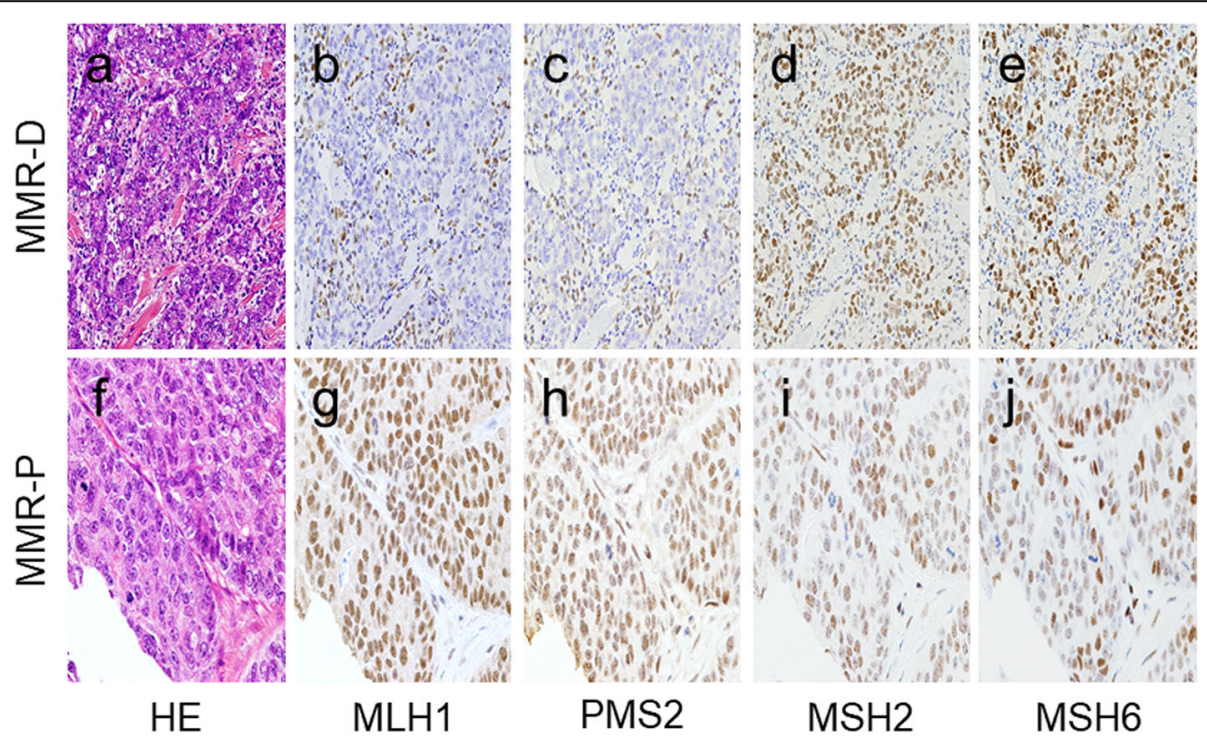

Fig. 1 Representative images and staining of MMR-P and MMR-D cases. Representative features in MMR-D (a) and MMR-P (f). Immunohistochemistry of four MMR proteins. Loss of MLH1/PMS2 ( $\mathbf{b}$ and $\mathbf{c}$ ) and expression of MSH2/MSH6 (d and $\mathbf{e}$ ) are shown in MMR-D. All four MMR proteins ( $\mathbf{g}, \mathbf{h}, \mathbf{i}$, and $\mathbf{j}$ ) are detected in MMR-P. (a and $\mathbf{f}, \mathrm{HE} ; \mathbf{b}$ and $\mathbf{g}, \mathrm{MLH} 1$ immunostaining; $\mathbf{c}$ and $\mathbf{h}, \mathrm{PMS} 2$ immunostaining; $\mathbf{d}$ and $\mathbf{i}$, MSH2 immunostaining; e and $\mathbf{j}$, MSH6 immunostaining) 


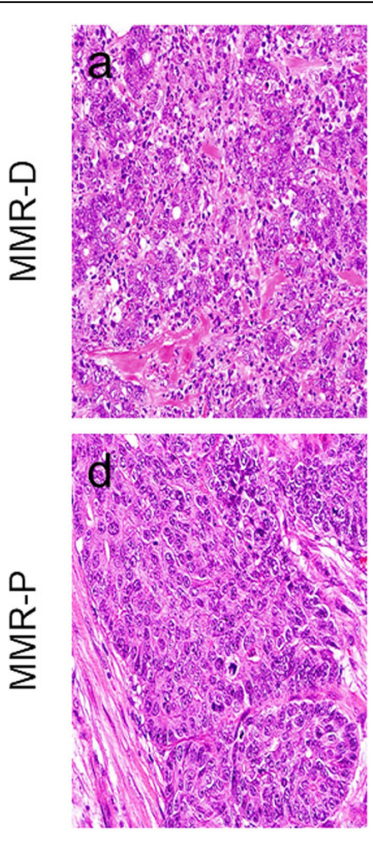

HE
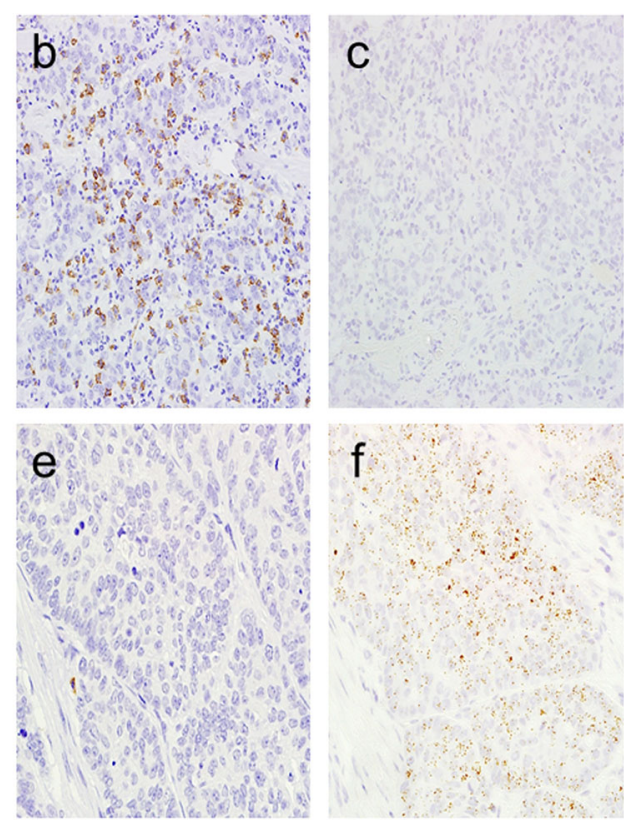

CD8

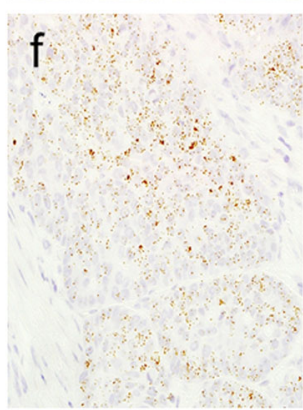

LGR5

Fig. 2 Representative images of $L G R 5$ and CD8 in MMR-P and MMR-D cases. Representative features in MMR-D (a) and MMR-P (d). In MMR-D, many CD8-positive lymphocytes were observed (b) and LGR5 expression was low (c). In MMR-P, few CD8-positive lymphocytes were observed (e) and LGR5 expression was high (f). (a and d $\mathbf{d}, \mathrm{HE} ; \mathbf{b}$ and $\mathbf{e}, \mathrm{CD} 8$ immunostaining; $\mathbf{c}$ and $\mathbf{f}, L G R 5$ RNAscope)

H-scores in MMR-D cases were significantly lower than those in MMR-P cases $(P=0.034)$ (Fig. 3).

\section{Correlation between LGR5 expression and $\beta$-catenin expression}

Previous studies on CRC showed that $\beta$-catenin is related to $L G R 5$, a cancer stem cell marker [17], and that $\beta$-catenin induces expression of LGR5 [18]. We thus analyzed the correlation between LGR5 $\mathrm{H}$-score and

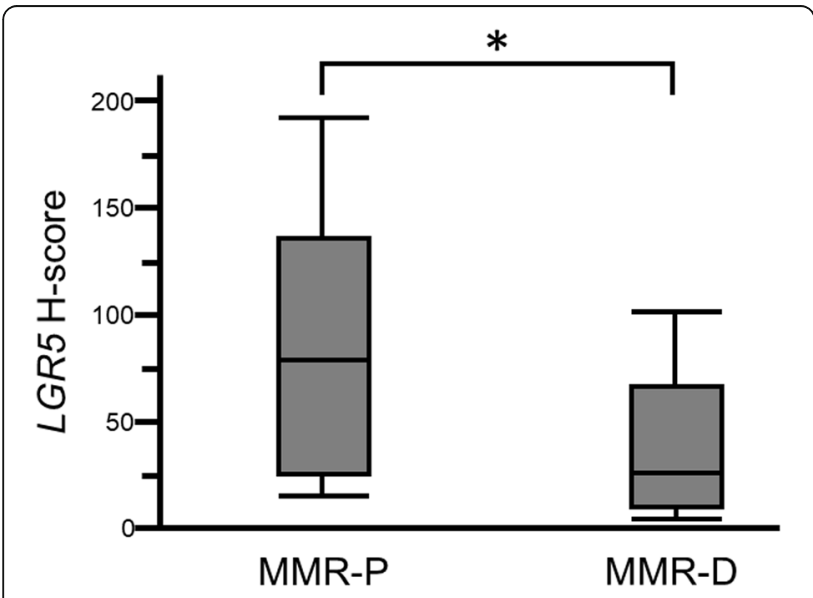

Fig. 3 Box plot of LGR5 H-scores in MMR-P and MMR-D. LGR5 Hscores in MMR-D cases were significantly lower than those in MMR-P cases $(P=0.034)$ expression of nuclear-translocated $\beta$-catenin. Mean nuclear $\beta$-catenin IHC scores in MMR-P cases and MMR$\mathrm{D}$ cases were 104.5 (81.3-285.8) and 23.9 (9.9-77.1), respectively. Nuclear $\beta$-catenin IHC scores in MMR-D cases were significantly lower than those in MMR-P cases $(P=0.002)$. In all cases, there was a positive correlation between $L G R 5 \mathrm{H}$-score and nuclear $\beta$-catenin IHC score $(\mathrm{r}=0.728, P<0.001)$ (Fig. 4$)$. Even in MMR-D and MMR-P cases, there was a positive correlation between LGR5 $\mathrm{H}$-score and nuclear $\beta$-catenin IHC score $(\mathrm{r}=$ $0.692, P=0.013$ and $\mathrm{r}=0.679, P=0.003$, respectively) (Fig. 4).

\section{Discussion}

Most CRC cases show multistep carcinogenesis based on an adenoma-carcinoma sequence [19]. In the first step, inactivation of APC induces aberrant $\mathrm{Wnt} / \beta$-catenin activation and contributes to tumorigenesis [19]. LGR5 is the target gene of $\beta$-catenin and TCF/LEF complex, and nuclear-translocated $\beta$-catenin affects LGR5 expression, as shown by previous reports and our current data $[18$, 20]. Deficiencies in MMR proteins are caused by genetic or epigenetic alterations in $M L H 1, P M S 2, M S H 2$, and MSH6. Deficiencies in MMR proteins induce MSI and lead to the acquisition of various gene mutations [21]. In MSI carcinoma, genetic mutations such as BRAF mutations have been reported, while driver mutations frequently observed in CRC are infrequent [22]. In this 

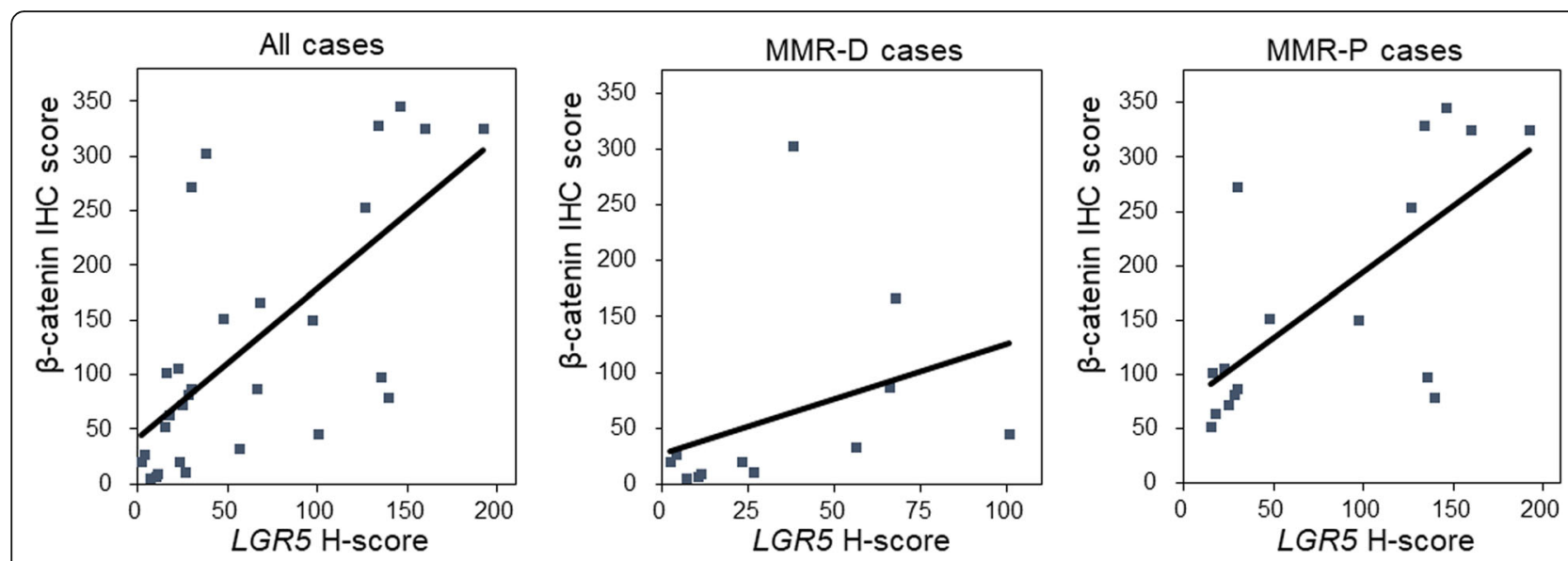

Fig. 4 Scatter plots of $L G R 5 \mathrm{H}$-score and nuclear $\beta$-catenin IHC scores. In all cases, MMR-D cases, and MMR-P cases, the scatter plots showed a positive correlation between LGR5 H-score and nuclear $\beta$-catenin IHC score $(r=0.728, P<0.001, r=0.692, P=0.013$, and $r=0.679$, $P=0.003$, respectively)

study, morphologically similar CRC cases were classified into two biologically different groups based on the expression of MMR proteins, and their LGR5 expression and clinicopathological features were analyzed.

Although the expression levels of LGR5 differed between MMR-D and MMR-P cases, the correlation with $\beta$-catenin in both types of cases proves the association between $\beta$-catenin and LGR5 expression. Low expression of LGR5 in MMR-D cases may be related to low $\beta$ catenin expression. Furthermore, these cases may be linked to abnormalities related to $\mathrm{Wnt} / \beta$-catenin signaling such as APC abnormalities.

There is controversy regarding the relationship between LGR5 expression and prognosis in CRC. One issue is that MMR-D and MMR-P cases were pooled and analyzed together in previous studies. Another issue is the LGR5 evaluation method. High expression of LGR5 has been reported to be associated with poor prognosis, but this remains controversial. It may be because many prognostic evaluations are performed by immunohistostaining. In a report using the RNA in situ hybridization method, high expression of LGR5 was observed in well differentiated CRC and showed better prognosis [4]. PD-CRC can arise through the adenomacarcinoma sequence or the serrated neoplasia pathway. It has been pointed out that there is a difference in LGR5 expression between the adenoma-carcinoma sequence and the serrated neoplasia pathway in RNA in situ hybridization [23] [24]. Because LGR5 is a target of Wnt/ $\beta$-catenin signaling that occurs during the adenoma-carcinoma sequence in CRC, LGR5 expression in MMR-P cases, which may involve the adenoma-carcinoma sequence, may be higher than that in MMR-D cases, which may involve the serrated neoplasia pathway [25].

A recent report described differences in the presence of LGR5-positive carcinoma stem cells based on differences in MMR protein expression [4]. However, no studies have previously analyzed LGR5 expression in detail in PD-CRC cases alone. In this study, we demonstrated that $L G R 5$ expression was significantly lower in MMR-D cases compared with MMR-P cases. The deficiency in MMR proteins contributed to an increase in tumor mutation burden in the tumor tissue. A characteristic of MSI carcinoma is the recruitment of infiltrating inflammatory cells due to increased antigen presentation by anti-cancer host immunity. A previous report [26] and our data also suggested that CD8+ TILs were present at high frequency in MMR-D CRC. The good prognosis of PD-CRC with MMR-D despite low expression of LGR5 may be due to differences in immune responses. CRC should be divided into MMR-D cases involving the serrated neoplasia pathway and MMR-P cases involving the adenoma-carcinoma sequence if $L G R 5$ is used as a prognostic marker, and LGR5 should be evaluated by RNA in situ hybridization. Analysis of a larger number of PD-CRC with MMR-D cases is warranted for more robust data. Although LGR5 is a stem cell marker for CRC, classification into several subgroups may lead to LGR5 being a more sensitive prognostic marker.

There are some limitations in our study. First, we did not examine mutations related to $\mathrm{Wnt} / \beta$-catenin signaling such as APC, so these may need to be compared with LGR5. Furthermore, it is necessary to investigate the relationship between APC abnormalities and LGR5 using cultured cells.

\section{Conclusions}

Our results reveal a relationship between LGR5 expression and MMR protein profiles in PD-CRC. A further study is warranted to confirm these findings. 


\section{Abbreviations}

LGR5: Leucine-rich repeat-containing G-protein-coupled receptor 5; MMR: Mismatch repair; PD: Poorly differentiated; CRC: Colorectal carcinoma; IHC: Immunohistochemistry; MMR-D: MMR-deficient; MMR-P: MMR-proficient; MSI: Microsatellite instability; TILs: Tumor-infiltrating lymphocytes; TMA: Tissue microarray

\section{Acknowledgments}

We are grateful to Yasuyo Shimojo, Masanobu Momose, Naoko Ogiwara, Akiko Inamura, Chitoshi Arai, Marina Nuno, Yasuhiro Kinugawa, Souya Ogasawara, Shun Kanai, and Kanade Wakabayashi at Shinshu University Hospital for their excellent technical assistance. We thank H. Nikki March, $\mathrm{PhD}$, and Alison Sherwin, PhD, from Edanz Group (www.edanzediting.com/ ac) for editing a draft of this manuscript.

\section{Authors' contributions}

TN participated in the design of the study, performed the pathological analysis, and drafted the manuscript. TU and MI helped with the pathological analysis. TU performed the statistical analysis. TN and YK conducted the immunohistochemistry. YM examined the clinical data of cases. HO and TU revised the draft manuscript critically for important intellectual content. All authors have read and approved the manuscript.

\section{Funding}

This study was partially supported by the Hokuto Foundation for Bioscience (grant awarded to T.U.). The funding body had no role in the study design, collection, analysis, or interpretation of data, or manuscript writing. The authors declare no conflicts of interest.

\section{Availability of data and materials}

All data generated and analyzed during the current study are available from the corresponding author on reasonable request.

\section{Ethics approval and consent to participate}

This study was approved by the Ethics Committee of Shinshu University School of Medicine (Approval Code: 4088). The requirement of informed consent was waived and an opt-out method was used due to the retrospective design of the study. The investigation was conducted in compliance with the Helsinki Declaration.

\section{Consent for publication}

Not applicable.

\section{Competing interests}

The authors declare that they have no competing interests.

\section{Author details}

'Department of Laboratory Medicine, Shinshu University School of Medicine, 3-1-1 Asahi, Matsumoto 390-8621, Japan. 'Department of Gastroenterology, Suwa Red Cross Hospital, Suwa, Japan. ${ }^{3}$ Department of Biomedical Laboratory Medicine, Shinshu University School of Medicine, Matsumoto, Japan.

Received: 6 February 2020 Accepted: 26 March 2020

Published online: 15 April 2020

\section{References}

1. Barker N, Clevers H. Leucine-rich repeat-containing G-protein-coupled receptors as markers of adult stem cells. Gastroenterology. 2010;138:168196.

2. de Sousa e Melo F, Kurtova AV, Harnoss JM, Kljavin N, Hoeck JD, Hung J, et al. A distinct role for $\mathrm{Lgr} 5(+)$ stem cells in primary and metastatic colon cancer. Nature. 2017;543:676-80.

3. Wu XS, Xi HQ, Chen L. Lgr5 is a potential marker of colorectal carcinoma stem cells that correlates with patient survival. World J Surg Oncol. 2012;10: 244

4. Jang BG, Kim HS, Chang WY, Bae JM, Kim WH, Kang GH. Expression profile of LGR5 and its prognostic significance in colorectal Cancer progression. Am J Pathol. 2018;188:2236-50.
5. Navarro M, Nicolas A, Ferrandez A, Lanas A. Colorectal cancer population screening programs worldwide in 2016: an update. World J Gastroenterol. 2017;23:3632-42.

6. Fearon ER, Vogelstein B. A genetic model for colorectal tumorigenesis. Cell. 1990;61:759-67.

7. Leggett $B$, Whitehall V. Role of the serrated pathway in colorectal cancer pathogenesis. Gastroenterology. 2010;138:2088-100.

8. Liang TJ, Wang HX, Zheng YY, Cao YQ, Wu X, Zhou X, et al. APC hypermethylation for early diagnosis of colorectal cancer: a meta-analysis and literature review. Oncotarget. 2017:8:46468-79.

9. Aaltonen LA, Salovaara R, Kristo P, Canzian F, Hemminki A, Peltomaki P, et al. Incidence of hereditary nonpolyposis colorectal cancer and the feasibility of molecular screening for the disease. N Engl J Med. 1998;338: $1481-7$.

10. Martin SA, Lord CJ. Ashworth a therapeutic targeting of the DNA mismatch repair pathway. Clin Cancer Res. 2010;16:5107-13.

11. de la Chapelle A, Hampel H. Clinical relevance of microsatellite instability in colorectal cancer. J Clin Oncol. 2010;28:3380-7.

12. Halvorsen TB, Seim E. Degree of differentiation in colorectal adenocarcinomas: a multivariate analysis of the influence on survival. J Clin Pathol. 1988:41:532-7.

13. Lagerstedt Robinson K, Liu T, Vandrovcova J, Halvarsson B, Clendenning M, Frebourg T, et al. Lynch syndrome (hereditary nonpolyposis colorectal cancer) diagnostics. J Natl Cancer Inst. 2007:99:291-9.

14. Kim JH, Rhee YY, Bae JM, Cho NY, Kang GH. Loss of CDX2/CK20 expression is associated with poorly differentiated carcinoma, the $\mathrm{CpG}$ island methylator phenotype, and adverse prognosis in microsatellite-unstable colorectal cancer. Am J Surg Pathol. 2013:37:1532-41.

15. Wong SC, Lo ES, Chan AK, Lee KC, Hsiao WL. Nuclear beta catenin as a potential prognostic and diagnostic marker in patients with colorectal cancer from Hong Kong. Mol Pathol. 2003;56:347-52.

16. Ukpo OC, Flanagan JJ, Ma XJ, Luo Y, Thorstad WL, Lewis JS Jr. High-risk human papillomavirus E6/E7 mRNA detection by a novel in situ hybridization assay strongly correlates with p16 expression and patient outcomes in oropharyngeal squamous cell carcinoma. Am J Surg Pathol. 2011;35:1343-50.

17. Fan XS, Wu HY, Yu HP, Zhou Q, Zhang YF, Huang Q. Expression of Lgr5 in human colorectal carcinogenesis and its potential correlation with betacatenin. Int J Color Dis. 2010;25:583-90.

18. Clevers H, Nusse R. Wnt/beta-catenin signaling and disease. Cell. 2012;149: $1192-205$.

19. Vogelstein B, Papadopoulos N, Velculescu VE, Zhou S, Diaz LA Jr, Kinzler KW. Cancer genome landscapes. Science. 2013;339:1546-58.

20. Van der Flier LG, Sabates-Bellver J, Oving I, Haegebarth A, De Palo M, Anti M, et al. The Intestinal Wnt/TCF Signature. Gastroenterology. 2007;132:62832.

21. Smyrk TC, Watson P, Kaul K, Lynch HT. Tumor-infiltrating lymphocytes are a marker for microsatellite instability in colorectal carcinoma. Cancer. 2001;91: 2417-22.

22. Ogino S, Nosho K, Kirkner GJ, Kawasaki T, Meyerhardt JA, Loda M, et al. CpG island methylator phenotype, microsatellite instability, BRAF mutation and clinical outcome in colon cancer. Gut. 2009;58:90-6.

23. Baker AM, Graham TA, Elia G, Wright NA, Rodriguez-Justo M. Characterization of LGR5 stem cells in colorectal adenomas and carcinomas. Sci Rep. 2015;5:8654

24. Jang BG, Kim HS, Kim KJ, Rhee YY, Kim WH, Kang GH. Distribution of intestinal stem cell markers in colorectal precancerous lesions. Histopathology. 2016;68:567-77.

25. Morgan RG, Mortensson E, Williams AC. Targeting LGR5 in colorectal Cancer: therapeutic gold or too plastic? Br J Cancer. 2018;118:1410-8.

26. Le DT, Uram JN, Wang H, Bartlett BR, Kemberling H, Eyring AD, et al. PD-1 blockade in tumors with mismatch-repair deficiency. N Engl J Med. 2015; 372:2509-20.

\section{Publisher's Note}

Springer Nature remains neutral with regard to jurisdictional claims in published maps and institutional affiliations. 